CLINICAL STUDY

\title{
Association of the type 2 deiodinase Thr92Ala polymorphism with type 2 diabetes: case-control study and meta-analysis
}

\author{
José Miguel Dora $^{1,2}$, Walter Escouto Machado ${ }^{1}$, Jakeline Rheinheimer ${ }^{1}$, Daisy Crispim ${ }^{1}$ and Ana Luiza Maia ${ }^{1}$ \\ ${ }^{1}$ Thyroid Section, Endocrine Division, and ${ }^{2}$ Clinical Pathology Division, Hospital de Clínicas de Porto Alegre, Universidade Federal do Rio Grande do Sul, \\ Ramiro Barcelos 2350, 90035-003 Porto Alegre, RS, Brazil
}

(Correspondence should be addressed to A L Maia; Email: almaia@ufrgs.br)

\begin{abstract}
Objective: The type 2 deiodinase (D2) is a key enzyme for intracellular triiodothyronine $\left(\mathrm{T}_{3}\right)$ generation. A single-nucleotide polymorphism in D2 (Thr92Ala) has been associated with increased insulin resistance in nondiabetic and type 2 diabetes (DM2) subjects. Our aim was to evaluate whether the D2 Thr92Ala polymorphism is associated with increased risk for DM2.

Design and methods: A case-control study with 1057 DM2 and 516 nondiabetic subjects was performed. All participants underwent genotyping of the D2 Thr92Ala polymorphism. Additionally, systematic review and meta-analysis of the literature for genetic association studies of D2 Thr92Ala polymorphism and DM2 were performed in Medline, Embase, LiLacs, and SciELO, and major meeting databases using the terms 'rs225014' odds ratio (OR) 'thr92ala' OR 'T92A' OR 'dio2 a/g'.

Results: In the case-control study, the frequencies of D2 Ala92Ala homozygous were $16.4 \%(n=173)$ versus $12.0 \%(n=62)$ in DM2 versus controls respectively resulting in an adjusted OR of $1.41(95 \%$ confidence intervals (CI) 1.03-1.94, $P=0.03$ ). The literature search identified three studies that analyzed the association of the D2 Thr92Ala polymorphism with DM2, with the following effect estimates: Mentuccia (OR 1.40 (95\% CI 0.78-2.51)), Grarup (OR 1.09 (95\% CI 0.92-1.29)), and Maia (OR 1.22 (95\% CI $0.78-1.92)$ ). The pooled effect of the four studies resulted in an OR 1.18 (95\% CI $1.03-1.36, P=0.02$ ).

Conclusions: Our results indicate that in a case-control study, the homozygosity for D2 Thr92Ala polymorphism is associated with increased risk for DM2. These results were confirmed by a metaanalysis including 11033 individuals, and support a role for intracellular $\mathrm{T}_{3}$ concentration in skeletal muscle on DM2 pathogenesis.
\end{abstract}

European Journal of Endocrinology 163 427-434

\section{Introduction}

Thyroxine $\left(\mathrm{T}_{4}\right)$, a major secretory product of the thyroid gland, needs to be converted to triiodothyronine $\left(\mathrm{T}_{3}\right)$ to exert its biological activity. Type 2 deiodinase (D2) catalyzes $\mathrm{T}_{4}$ to $\mathrm{T}_{3}$ conversion, and plays a critical role in maintaining intracellular $\mathrm{T}_{3}$ levels in specialized tissues, such as the anterior pituitary, $\mathrm{CN}$, and brown adipose tissue (BAT) (1). D2 gene (DIO2) expression has also been reported in pituitary, thyroid, placenta, heart and skeletal muscle, and testis (2-8). Recently, it has been suggested that D2 also contributes for a fraction of the serum $\mathrm{T}_{3}$ levels in euthyroid and hypothyroid individuals (9).

Previous studies have demonstrated that polymorphisms in the deiodinase genes might interfere in the phenotypic expression of these enzymes $(6,10)$. Interestingly, a study described a single-nucleotide polymorphism in D2, in which a threonine (Thr) changes to alanine (Ala) at codon 92 (D2 Thr92Ala) was associated with $\sim 20 \%$ lower glucose disposal rate in nondiabetic subjects (11). In addition, the Ala allele in homozygosis was associated with greater insulin resistance in type 2 diabetes (DM2) patients and decreased enzyme activity in human tissues (6). The mechanism of reduced D2 activity, however, is still not clear since no significant changes in the biochemical properties of the mutant enzyme have been detected (12), thus suggesting that this variant could only be a marker for abnormal DIO2 expression. The D2 Thr92Ala polymorphism has also been linked to increased risk for osteoarthritis (13), hypertension (14), Graves' disease (15), intelligence quotient alterations associated with iodine deficiency (16), psychological well-being and response to $\mathrm{T}_{3}$ or $\mathrm{T}_{4}$ treatment (17), and decreased bone mass and higher bone turnover (18). Intriguingly, most of these associations are independent of serum thyroid hormone levels, which highlight the importance of local regulation of thyroid hormones in peripheral tissues.

DM2 is a heterogeneous group of disorders, with varying degrees of insulin insufficiency and insulin 
resistance, which result in increased blood glucose concentrations. At last, insulin resistance results either from inappropriately increased hepatic gluconeogenesis and/or decreased glucose disposal rate in tissues such as skeletal muscle and adipose tissue. Glucose transporter type 4 (GLUT4), the insulin-responsive glucose transporter, mediates the rate-limiting step of glucose metabolism. Thyroid hormones are known to upregulate the expression of GLUT4 in skeletal muscle, and consequently increase glucose uptake (19). Thus, one could speculate that a lower intracellular D2-generated $\mathrm{T}_{3}$ in skeletal muscle could create a state of relative intracellular hypothyroidism, decreasing the expression of genes involved in energy use, such as GLUT4, resulting in increased insulin resistance. Nevertheless, population-based studies failed to demonstrate an association between the D2 Thr92Ala polymorphism and increased risk for DM2 (20-22).

Clinical and experimental data support a biological plausibility for a role of the D2 Thr92Ala variant in predisposition to DM2, a heterogeneous disease with many environmental and genetic factor interactions. In this setting, where both environment factors and multiple genes play a role in the pathophysiology, it is not unexpected that genetic association studies fail to show an association, even when it actually exists. Accordingly, diabetes has been called 'a geneticist's nightmare' and, in this context, a huge number of patients may be needed to clarify the collaboration of a single polymorphism for this polygenic disease (23). Here, we sought to further test the hypothesis that homozygosity for the D2 Thr92Ala polymorphism is associated with increased risk for DM2. In an attempt to address the study limitations highlighted above, we performed a case-control study in a Brazilian population and a meta-analysis of the literature on the subject.

\section{Research design and methods}

\section{Case-control study}

DM2 population The sample population consisted of 1057 DM2 patients participating in a multicenter study that started recruiting patients in Southern Brazil in 2002. That study aimed to evaluate risk factors for DM2 and its complications. Initially, it included four centers located at general hospitals in the State of Rio Grande do Sul, namely Grupo Hospitalar Conceição, Hospital São Vicente de Paula, Hospital Universitário de Rio Grande, and Hospital de Clínicas de Porto Alegre. The detailed description of that study can be found elsewhere (24). The sample population presented here includes a subgroup of 183 patients described in a previous study (6).

All patients were of European ancestry (mostly descendants of Portuguese, Spanish, Italians and Germans). The ethnic group was defined on the basis of self-classification and subjective classification (skin color, nose and lip shapes, hair texture, and family history). A standard questionnaire was used to collect information about age, age at DM2 diagnosis, and drug treatment. All patients underwent physical and laboratory evaluations. They were weighed without shoes and in light outdoor clothes, and had their height measured. Body mass index was calculated as follows: weight $(\mathrm{kg}) /$ height $(\mathrm{m})^{2}$. Blood pressure (BP) was measured twice after a 5-min rest in the sitting position using a mercury sphygmomanometer (Korotkoff phases I and $\mathrm{V})$. The mean value of two measurements was used to calculate systolic and diastolic BP.

Diabetes was defined as treatment with either insulin or an oral hypoglycemic agent or a fasting plasma glucose of at least $126 \mathrm{mg} / \mathrm{dl}(7.0 \mathrm{mmol} / \mathrm{l})$ at two or more examinations, 2 -h $75-\mathrm{g}$ oral glucose tolerance test plasma glucose of at least $200 \mathrm{mg} / \mathrm{dl}(11.1 \mathrm{mmol} / \mathrm{l})$, or random plasma glucose of $200 \mathrm{mg} / \mathrm{dl}(11.1 \mathrm{mmol} / \mathrm{l})$ or higher (25). Patients were classified as DM2 based on patients' age (30-year-old or older), upon the need or not for insulin at diagnosis, and absence of ketones in the urine. Microvascular and macrovascular complications were accessed at study entry.

Nondiabetic control population A group of 516 nondiabetic volunteers attending the blood donation facility of Hospital de Clínicas de Porto Alegre (Porto Alegre, Brazil) constituted our control group. A standard questionnaire was used to collect information about age, sex, skin color, and presence of comorbidities (e.g. systemic arterial hypertension) and drug treatment from controls.

Protocol ethical approval The information obtained from the study did not influence the patient's diagnosis or treatment. The local ethics committee approved the protocol, and all patients signed an informed consent form.

Laboratory tests In DM2 patients, a serum sample was collected after a 12-h fast. Glucose levels were determined by a glucose oxidase method and HbA1c by an ion-exchange HPLC procedure (Merck-Hitachi L-9100 HbA1c analyzer, Merck; reference range: $2.7-4.3 \%$ ). Serum insulin was measured by electrochemiluminescence (ElecsysR Systems 1010/2010/modular analytics E170, Roche Diagnostics). The intra- and inter-assay coefficients of variation were 1.5 and $4.9 \%$ respectively. Insulin sensitivity was estimated by homeostasis model assessment $(\mathrm{HOMA}=$ fasting insulin (milliunits per milliliter) $\times$ fasting glucose (millimoles per liter)/22.5), as recently described and validated (26). Additionally, triglyceride and cholesterol levels were measured by enzymatic methods, and low-density lipoprotein cholesterol (LDL) was calculated using the Friedewald equation: (LDL cholesterol $=$ total cholesterol HDL cholesterol - triglycerides/5). 
In nondiabetic subjects, no laboratory measures were performed.

Genotyping DNA was extracted from peripheral blood leukocytes by a standardized salting out procedure. Primers and probes contained in the Human Custom TaqMan Genotyping Assay $40 \times$ (Applied Biosystems, Foster City, CA, USA) were used for genotyping our samples. One allelic probe was labeled with VIC dye, and the other was labeled with FAM dye. The reactions were conducted in a 96-well plate, in a total 5- $\mu$ l reaction volume using 2 ng genomic DNA, TaqMan Genotyping Master Mix $1 \times$ (Applied Biosystems), and Custom TaqMan Genotyping Assay $1 \times$. The plates were then positioned in a real-time PCR thermal cycler (7500 Fast Real PCR System; Applied Biosystems) and heated for $10 \mathrm{~min}$ at $95^{\circ} \mathrm{C}$ followed by 50 cycles of $95^{\circ} \mathrm{C}$ for $15 \mathrm{~s}$ and $63{ }^{\circ} \mathrm{C}$ for $1 \mathrm{~min}$. Fluorescence data files from each plate were analyzed using automated allele-calling software (SDS 2.1; Applied Biosystems).

Patients were classified in groups of Ala/Ala or Ala/Thr-Thr/Thr according to the presence of the Ala allele. All amplification reactions were performed twice. The genotyping success was more than 95\%, with a calculated error rate based on PCR duplicates of $0 \%$.

Statistical analyses Results were expressed as frequencies, mean \pm s.D. (27) or median and percentile 25-75 (P25-75). Allelic frequencies were determined by gene counting, and departures from the Hardy-Weinberg equilibrium were verified using $\chi^{2}$ tests. Clinical and laboratory data were compared using $\chi^{2}$, unpaired Student's t-test, Mann-Whitney $U$ test, ANOVA, Kruskal-Wallis $H$ test, or multiple logistic regression analysis as appropriate. A two-tailed $P<0.05$ was considered statistically significant, and all analyses were performed by SPSS version 15.0 (SPSS, Chicago, IL, USA).

\section{Meta-analysis}

Search strategy The electronic databases Medline, Embase, LiLacs, and SciELO were searched for studies of genetic association between the D2 Thr92Ala polymorphism and DM2. We also searched the abstracts of the major diabetes and thyroid meetings over the last 4 years. We limited the search to humans and used the following strategy: 'rs225014' odds ratio (OR) 'thr92ala' OR 'T92A' OR ‘dio2 a/g'. The reference lists of all identified articles were also searched, and authors of included studies were consulted to obtain additional information when needed. For inclusion in the metaanalysis, we considered as attending the inclusion criteria both: i) observational studies (cohort, casecontrol, and cross-sectional studies) on the D2 Thr92Ala polymorphism and ii) that included patients with and without DM2.
Two investigators (J M D and W E M), blinded to each other's rating, independently assessed study eligibility. All data were independently abstracted in duplicate using a standardized abstraction form. Differences in data extraction were resolved by a third party (A L M) and by referencing the original publication.

\section{Statistical analyses}

Data from the selected studies were retrieved and annotated according to the presence or the absence of DM2. The frequencies of each genotype of the D2 Thr92Ala polymorphism in DM2 and in nondiabetic controls from all studies were pooled. The OR and their 95\% confidence intervals (95\% CI) for individual studies, and for the pooled effect were calculated with the Mantel-Haenszel, the DerSimonian and Laird, and Peto's methods, using random effect and fixed effect models. Heterogeneity was tested with the Cochran $Q$ test and inconsistency accessed through the $I^{2}$. Additionally, sensitivity analysis was performed omitting one study at a time to evaluate the influence of each study on the pooled estimate. We used the programs Review Manager 5 (28) and MIX version 1.7 (29) for data analysis, and the study was designed and described in accordance with current guidelines (30-32).

\section{Results}

\section{Case-control study}

The baseline characteristics of the 1057 DM2 patients and 516 nondiabetic control subjects regarding age in years and sex were respectively the following: mean age $59.3 \pm 10.0$ (age at diagnosis $47.4 \pm 10.9$ ) and 46.2 $\pm 8.8, P=0.02$; females comprised $53 \%(n=558)$ and $37 \%(n=191)$ of study groups, $P<0.005$ (Table 1$)$.

The frequency of the minor Ala allele was 0.38 in DM2 patients and control subjects. In the DM2 group, $381(36 \%)$ individuals were homozygous for the Thr allele, $503(47.6 \%)$ were heterozygous (Thr/Ala), and $173(16.4 \%)$ were homozygous for the Ala allele. In the group control, 195 subjects for the Thr allele $(37.8 \%)$, $259(50.2 \%)$ were heterozygous, and $62(12.0 \%)$ were homozygous for Ala allele. The genotypes were in Hardy-Weinberg equilibrium $(P=0.96)$. The frequency of homozygotes for the Ala allele was significantly higher in the DM2 group than in controls (16.4 vs $12.0 \%$ respectively; $P=0.03)$. This resulted in an OR of $1.43(95 \%$ CI $1.05-1.96, P=0.03)$ for the Ala/Ala genotype in DM2 patients. Because the DM2 and control groups differed by age and sex (Table 1), we performed a multiple logistic regression analysis with age, sex, and genotype as independent variables and DM2 as the dependent variable. The Ala/Ala genotype remained significantly associated with DM2 with an adjusted OR of 1.41 (95\% CI 1.03-1.94, $P=0.03)$. 
Table 1 Characteristics of type 2 diabetes and nondiabetic individuals (controls). Data are expressed as mean \pm s.D. or median (P25-P75).

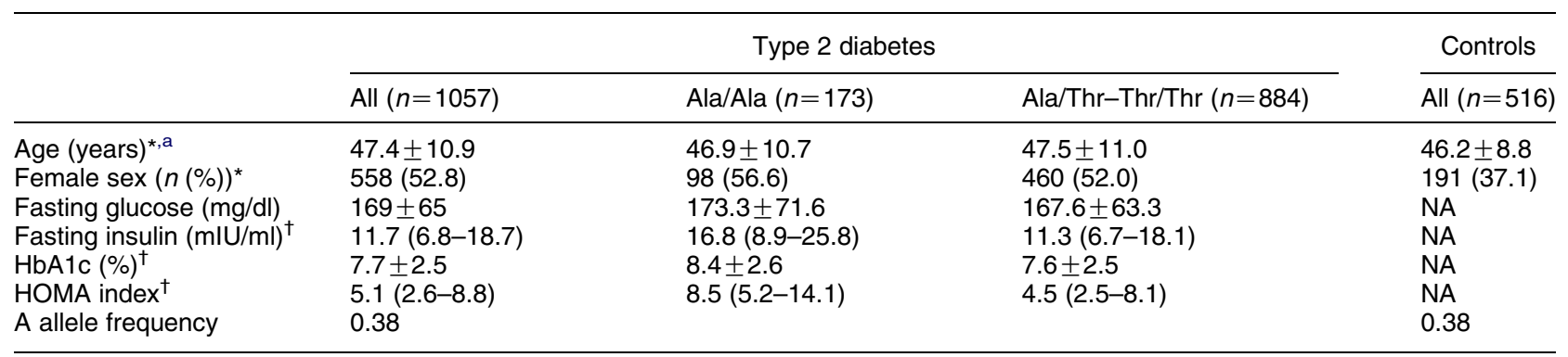

$\mathrm{NA}$, not available; HOMA, homeostasis model assessment (fasting insulin $(\mathrm{mlU} / \mathrm{ml}) \times$ fasting glucose $(\mathrm{mmol} / \mathrm{l}) / 22.5)$. To convert glucose from $\mathrm{mg} / \mathrm{dl}$ to $\mathrm{mmol} / \mathrm{l}$, divide by 18 or multiply by 0.055 . * Statistically significant comparisons between all type 2 diabetes versus nondiabetic subjects $(P=0.02$ for age and $P<0.005$ for sex). 'T tatistically significant comparisons between Ala/Ala versus Ala/Thr-Thr/Thr genotypes $(P=0.01$ for fasting insulin, $P=0.01$ for $\mathrm{HbA} 1 \mathrm{c}$, and $P<0.005$ for HOMA index). Statistical analysis: unpaired Student's $t$-test for age, fasting glucose, and HbA1c; Mann-Whitney $U$ test for fasting insulin and HOMA; and $\chi^{2}$ test for sex and A allele frequency.

${ }^{a}$ For type 2 diabetes, age at diagnosis was used for comparison with age of controls.

Assuming a recessive model, patients with Ala/Thr and Thr/Thr genotypes were grouped and compared with patients with Ala/Ala genotype. The diabetes duration (10 (5-17) years), systolic $(142 \pm 23 \mathrm{mmHg})$ and diastolic $(85 \pm 13 \mathrm{mmHg}) \mathrm{BP}$, microvascular $(67 \%)$ and macrovascular (58\%) complications, renal function (creatinine $0.9(0.8-1.1) \mathrm{mg} / \mathrm{dl}$ ), and nonglycemic metabolic control (high-density lipoprotein cholesterol $45 \pm 12 \mathrm{mg} / \mathrm{dl}$; LDL cholesterol $129 \pm 42 \mathrm{mg} / \mathrm{dl}$; total cholesterol $208 \pm 46 \mathrm{mg} / \mathrm{dl}$; and triglycerides 150 (105-217) $\mathrm{mg} / \mathrm{dl}$ ) were similar across the D2 genotypes in the type 2 diabetes patients (data not shown). There was a tendency toward higher fasting glucose levels in the DM2 patients harboring the Ala/Ala genotype (fasting glucose $173 \pm 71$ vs $167 \pm 63 \mathrm{mg} / \mathrm{dl}$, for Ala/Ala versus Ala/Thr-Thr/Thr respectively $P=0.06$ ). Confirming our previous report, subjects with the Ala/Ala genotype had increased insulin levels (fasting insulin $16.8(8.9-25.8)$ vs $11.3(6.7-18.1)$ $\mathrm{mIU} / \mathrm{ml}$, for Ala/Ala versus Ala/Thr-Thr/Thr respectively $P=0.01$ ) and increased insulin resistance (HOMA index $8.5(5.2-14.1)$ vs $4.5(2.5-8.1)$, for Ala/Ala versus Ala/Thr-Thr/Thr respectively $P<0.005)$. Moreover, the glycemic control, assessed by $\mathrm{HbA} 1 \mathrm{c}$ levels, were worst in the group of patients with the Ala/Ala genotype (HbA1c $8.4 \pm 2.6$ vs $7.6 \pm 2.5 \%$ respectively $P=004)$, despite comparable antidiabetic therapy (metformin 42.7 vs $37.7 \%, P=0.44$; sulfonylureas 34.7 vs $31.7 \%, P=0.60$; insulin 41.4 vs $40.2 \%$, $P=0.82$ for Ala/Ala versus Ala/Thr-Thr/Thr respectively). Eighty-four patients ( $8 \%$ ) were not receiving drug therapy (diet/exercise alone).

\section{Meta-analysis}

A literature search using the terms 'rs225014' OR 'thr92ala' OR 'T92A' OR 'dio 2 a/g' retrieved 28 articles dealing with D2 Thr92Ala polymorphism. Out of them, 18 studies were excluded because they did not include data on the presence or the absence of diabetes, four because the presence of diabetes was an exclusion criteria, one because it included only diabetic patients, and one because data of the diabetic and nondiabetic populations was nonextractable. Thus, we identified three observational studies (two cross-sectional and one case-control) that analyzed the Thr92Ala polymorphism in DM2 and nondiabetic subjects (Fig. 1) (20-22). Therefore, the meta-analysis included four studies: three identified through database search, and our case-control study. The demographic and glycemic characteristics of the populations included in each study are described in Table 2.

The study of Mentuccia et al. (20) looked at the Amish population (OR 1.40, 95\% CI 0.78-2.51); Maia et al. (21) analyzed data from the Framingham Study (OR 1.22, 95\% CI 0.78-1.92); and Grarup et al. (22) studied a large cohort of Danish (OR 1.09, 95\% CI 0.92-1.29). Neither heterogeneity $(Q=2.64, \quad P=0.45)$ nor

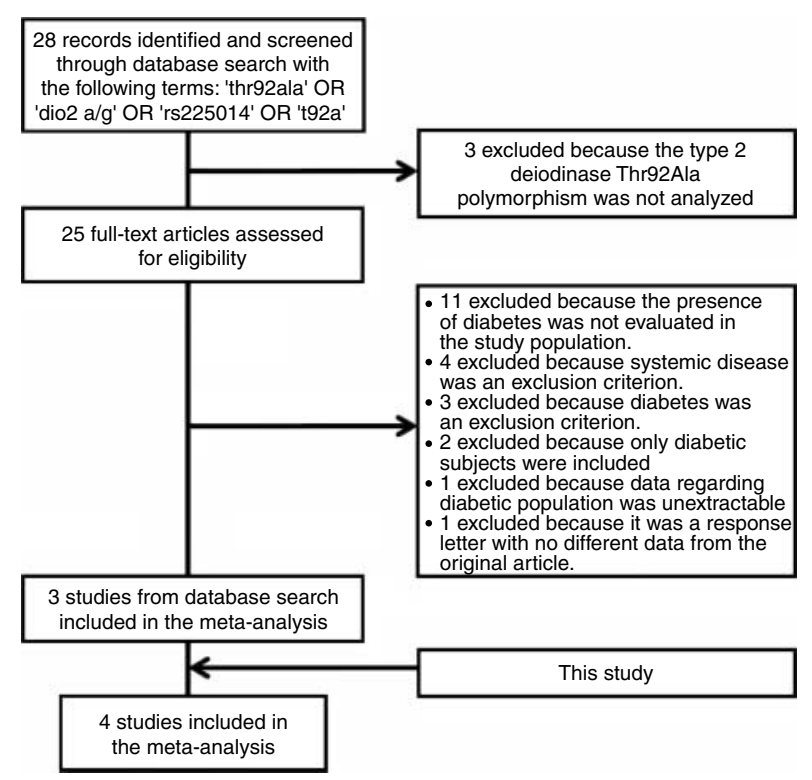

Figure 1 Flowchart of search results for the meta-analysis of the D2 Thr92Ala polymorphism association with type 2 diabetes. 
Table 2 Characteristics of the populations of the four studies that evaluated the genetic association of the type 2 deiodinase Thr92Ala polymorphism with type 2 diabetes. Data are expressed as mean \pm s.D.

\begin{tabular}{lllll}
\hline Author (reference) & Mentuccia et al. (20) & Maia et al. (21) & Grarup et al. (22) & This study \\
\hline Year of publication & 2005 & 2007 & 2007 & 2010 \\
Individuals studied $(n)$ & 1268 & 1631 & 7000 & 1573 \\
Type 2 diabetes subjects $(n(\%))$ & $179(14.1)$ & $170(10.4)$ & $1405(20.1)$ & $1057(67.2)$ \\
Age (years) & $45.5 \pm 0.6$ & $62.0 \pm 9.0$ & $48.5 \pm 9.2$ & $54.8 \pm 11.4$ \\
Female sex $(n(\%))$ & $707(55.8)$ & $841(51.6)$ & $3563(50.9)$ & $750(47.7)$ \\
BMl $\left(\mathrm{kg} / \mathrm{m}^{2}\right)$ & $27.2 \pm 0.2$ & $28.2 \pm 5.2$ & $29.6 \pm 5.3^{\mathrm{a}}$ & $28.9 \pm 5.0^{\mathrm{a}}$ \\
Fasting glucose (mg/dl) & $91 \pm 1$ & $106 \pm 27$ & $\mathrm{NA}$ & $169 \pm 65^{\mathrm{a}}$ \\
HbA1c (\%) & $5.2 \pm 0.1$ & $5.7 \pm 1.0$ & $7.8 \pm 1.7^{\mathrm{a}}$ & $7.7 \pm 2.5^{\mathrm{a}}$ \\
A allele frequency & 0.30 & 0.37 & 0.36 & 0.38 \\
\hline
\end{tabular}

BMI, body mass index (weight $(\mathrm{kg}) /$ height $(\mathrm{m})^{2}$ ); NA, not available. To convert glucose from $\mathrm{mg} / \mathrm{dl}$ to $\mathrm{mmol} / \mathrm{l}$, divide by 18 or multiply by 0.055 . ${ }^{\mathrm{a}}$ Data from the type 2 diabetes subjects of the study.

inconsistency $\left(I^{2}=0 \%\right)$ across studies was detected. Combining the results of the four studies, applying the fixed effect model resulted in an estimate Peto pooled OR of 1.18 (95\% CI 1.03-1.36, $P=0.02$; Fig. 2). The results were very similar (all statistically significant), when using the Mantel-Haenszel, the DerSimonian and Laird methods, and the random effect model (data not shown).

The weight of each study on the pooled estimate was as follows: Mentuccia 5.6\%, Maia 9.3\%, Grarup 65.3\%, and ours $19.7 \%$. Omission of one study at a time was performed to verify the impact of each study on the estimate effect. Analysis with the omission of the studies of Mentuccia, Maia, Grarup, and ours resulted in similar effect estimates, with calculated OR of 1.18 (95\% CI 1.00-1.40, change in OR estimate +0.4\%), $1.21(95 \%$ CI 0.99-1.47, change in OR estimate $+2.8 \%$ ), 1.37 (95\% CI 1.08-1.73, change in OR estimate $+16.2 \%$ ), and 1.12 (95\% CI 0.96-1.31, change in OR estimate $-4.7 \%$ ) respectively. All the calculations of the sensitivity analysis provided effect estimates similar to the pooled OR of the four studies, reinforcing the homogeneity between the studies included in our metaanalysis, and excluding a dominant influence of one study in the magnitude of the effect estimate.

\section{Discussion}

DM2 is a highly heterogeneous disease with multiple environmental and genetic factors involved in its pathogenesis. Here, we have performed a case-control study and a meta-analysis of genetic association studies, which demonstrate that homozygosis for the Ala allele of the single-nucleotide polymorphism Thr/Ala in codon 92 of the D2 is associated with increased risk for DM2 in the general population.

D2 is a key enzyme in determining intracellular $\mathrm{T}_{3}$ concentration, and might have a critical role in metabolic activity of skeletal muscle, analogous to its role in BAT $(1,33,34)$. Chronic adrenergic stimulation in adult humans was found to increase both resting energy expenditure (35) and serum $\mathrm{T}_{3}$ to $\mathrm{T}_{4}$ ratio (33), suggesting the existence of an adrenergic-dependent $\mathrm{T}_{4}$ to $\mathrm{T}_{3}$ conversion pathway (36). In addition, in patients receiving $\mathrm{T}_{4}$ replacement, resting energy expenditure correlated directly with free $\mathrm{T}_{4}$ and inversely with serum TSH but, interestingly, not with serum $\mathrm{T}_{3}$ (34). These data are consistent with a role for $\mathrm{T}_{4}$ via $\mathrm{D} 2$ dependent intracellular $\mathrm{T}_{3}$ production in skeletal muscle as a significant physiological determinant of energy

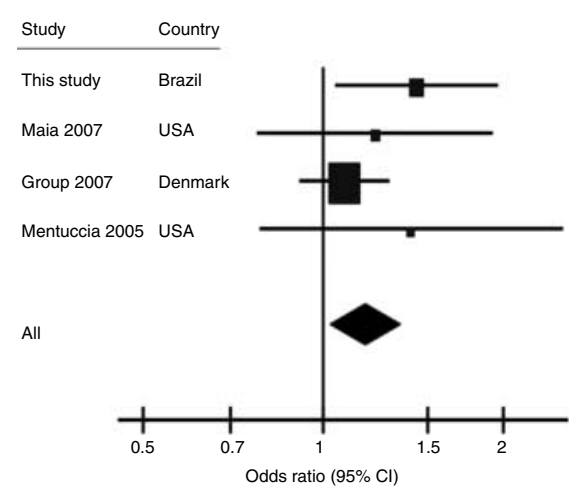

Test for heterogeneity: $P=0.45$

Inconsistency: $I^{2}=0 \%$

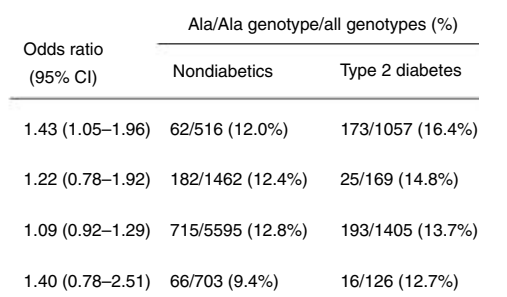

$1.18(1.03-1.35) \quad 1025 / 8276(12.4 \%) \quad 407 / 2757(14.8 \%)$
Figure 2 Individual and pooled odds ratios (OR) and $95 \%$ confidence intervals (95\% $\mathrm{Cl}$ ) estimate for type 2 diabetes association with the Ala/Ala genotype of the type 2 deiodinase. Statistical analysis: pooled OR estimated through the Peto method (fixed effect model); heterogeneity tested with the Cochran $Q$ test $(Q=2.64, P=0.45)$ and inconsistency accessed through the $I^{2}\left(I^{2}=0 \%\right)$. 
expenditure in humans. Moreover, recent evidence shows that BAT is present and active in adult humans, and that D2-mediated $\mathrm{T}_{3}$ production in this tissue might be important for thermal adaptation and metabolic activity (37).

Previous studies demonstrated that homozygosity for the Ala allele of the D2 Thr92Ala polymorphism was associated with $\sim 20 \%$ lower glucose disposal rate in nondiabetic Caucasians (11). The frequency of the variant allele was also found to be increased in some ethnic groups, such as Pima Indians and MexicanAmericans, who also have a higher prevalence of insulin resistance (11). Accordingly, we have previously demonstrated that the D2 Ala/Ala genotype was associated with increased insulin levels and HOMA index in patients with DM2, whereas decreased D2 activity was found in sample biopsies of individuals harboring this genotype (7). Here, we have further confirmed the D2 Ala/Ala genotype association with increased insulin resistance (increased HOMA index), and demonstrated that this genotype is also associated with worse glycemic control (increased HbA1c levels) in a cohort of 1057 DM2 subjects.

Taken together, these observations raised the hypothesis that the D2 Thr92Ala polymorphism would be associated with increased risk for DM2. However, despite a statistically nonsignificant tendency, all studies performed on this subject have failed to demonstrate such an association (Fig. 2). Using crosssectional designs, Mentuccia et al. (20) have studied 1268 subjects of the Old Order of Amish (Philadelphia, PA, USA), whereas Maia et al. (21) evaluated a subset of 1631 subjects from the Offspring Cohort of the Framingham Heart Study (Framingham, MA, USA). DM2 comprised 14.1\% (179 individuals) and 10.4\% (170 individuals) of the populations of the Mentuccia and Maia studies respectively.

Grarup et al. (22) studied 7342 white subjects from Glostrup and Copenhagen (Denmark), in a mixed casecontrol and cross-sectional design. In this study, in the unadjusted analyses, an association was verified between the D2 Ala/Ala genotype and glycemic traits of insulin resistance: an increased area under serum insulin curve during the oral glucose tolerance test and elevated fasting plasma glucose in the D2 Ala/Ala group. No increased risk for DM2 was found. It is interesting to highlight, however, that the control group of this study comprised of patients younger than the cases (age of $46.4 \pm 8.8$ vs $51.3 \pm 11.2$ years, for controls versus DM2 patients at diagnosis respectively; difference 4.9 years $(95 \%$ CI 4.3-5.5), $P<0.001)$.

The contribution of a single gene to a polygenic disease is determined by the prevalence of the implicated allele and the magnitude of the association with the condition (38). In this context, underpowerment is a concern in genetic association studies in a disease such as DM2. For instance, despite all the research efforts in this area, the DM2 has only a $6 \%$ estimated proportion of heriditability explained by the 19 loci associated with the disease $(27,38)$. The magnitude of effect of the described genetic variants associated with the disease is of OR 1.14; 1.12-1.16 (median; P25-75) (23). In this scenario, the assumptions made in previous studies $(21$, 22) for a presumed magnitude of a Thr92Ala polymorphism association with DM2 of OR 1.9 and 1.3 might be over estimated.

Therefore, assuming a smaller magnitude of effect for the D2 Thr92Ala polymorphism on DM2 risk and the need of a large number of patients to rule out a role of this gene, we have designed a case-control study that included a large number of type 2 diabetic patients (1057 individuals) and performed a meta-analysis of the data on the subject. In the case-control study, the frequency of the Ala allele in homozygosis was significantly higher in DM2 than in control subjects (16.4 vs $12.0 \%, P=0.03$ ). These frequencies, after adjusting for sex and age, resulted in an OR of 1.41 (95\% CI 1.03-1.94) for Ala/Ala genotype in DM2 patients. The literature search identified one case-control and two cross-sectional studies on the subject, detailed above (Table 2). Despite the different designs employed (case-controls and cross-sectionals) and the different genetic background of the populations (North-Americans, Europeans, and South-Americans), the results showed neither inconsistency nor heterogeneity in the pooled data from the four studies. The direction of the estimate was same in the four studies, and moreover, the sensitivity analysis demonstrated that the effect estimate was consistent across studies. The metaanalysis OR of 1.18 (95\% CI 1.03-1.35) reflects an increased risk for DM2 attributable to the homozygosity of the Ala allele of around $10 \%$ (95\% CI 1-21\%). This is a meaningful magnitude of effect for a single polymorphism in a polygenic disease like DM2. As an example, the Ala allele of the well-characterized Pro12Ala substitution in the peroxisome proliferatoractivated receptor $\gamma(P P A R \gamma$ or PPARG) gene accounts for a near 20\% decreased risk for DM2 (39), and most of the other genes implicated in DM2 risk have magnitudes of effects $<10 \%$ (23).

The finding that D2 single-nucleotide polymorphism is associated with increased risk for DM2 has relevant clinical implications. One notable aspect is that most of the genetic loci that were identified in association studies of DM2 seem to affect insulin secretion (23), not insulin sensitivity such is this case. In the context of the current pandemics of obesity and obesity-attributable insulin resistance, the identification of a pathogenic genetic trait that contributes to increased insulin resistance and increased risk for DM2 constitutes an important step for better understanding of the mechanism of disease. Indeed, these results might support a role for intracellular $\mathrm{T}_{3}$ concentration in DM2 pathogenesis and might constitute a potential target to specific therapies $(1,7,9)$. 
Despite all our efforts, we are aware that some factors unrelated to the D2 Thr92Ala polymorphism could have interfered with the findings of this study. Metaanalysis method is notoriously prone to publication bias, and although we have attempted to trace unpublished observations, we cannot assure that small negative studies were overlooked. Moreover, one of the identified studies was not included in this metaanalysis because data regarding diabetic population was unextractable (40).

In conclusion, our results demonstrate that the Ala/Ala genotype of D2 is associated with increased risk for DM2. In a case-control study of 1573 patients and in a meta-analysis of four studies with 11033 subjects, this genotype was associated with increased risk for DM2 in the general population, a finding that might represent an advance in understanding the genetic contribution to the pathogenesis of the disease.

\section{Declaration of interest}

The authors declare that there is no conflict of interest that could be perceived as prejudicing the impartiality of the research reported.

\section{Funding}

Conselho Nacional de Desenvolvimento Científico e Tecnológico (CNPq), and Fundo de Incentivo a Pesquisa (FIPE), Brazil.

\section{Acknowledgements}

We are very grateful to Dr Niels Grarup and Dr Francesco Celi Groups for the kind provision/confirmation of data on the Thr92Ala polymorphism genotypes prevalence in their studies. We thank Murilo A Leie and Dr Luis E Rohde for the kind donation of control DNA samples, Dr Carisi A Polanczyk for help in the EMBASE database analysis, Rodrigo A Ribeiro for help in statistical analysis, and Dr Luis Henrique Canani for valuable discussions. This work was made possible by grants from Conselho Nacional de Desenvolvimento Científico e Tecnológico (CNPq), and Fundo de Incentivo a Pesquisa (FIPE), Brazil.

\section{References}

1 Bianco AC, Maia AL, Da Silva WS \& Christoffolete MA. Adaptive activation of thyroid hormone and energy expenditure. Bioscience Reports 200525 191-208.

2 Croteau W, Davey JC, Galton VA \& St Germain DL. Cloning of the mammalian type II iodothyronine deiodinase. A selenoprotein differentially expressed and regulated in human and rat brain and other tissues. Journal of Clinical Investigation 1996 98 405-417.

3 Itagaki Y, Yoshida K, Ikeda H, Kaise K, Kaise N, Yamamoto M, Sakurada T \& Yoshinaga K. Thyroxine $5^{\prime}$-deiodinase in human anterior pituitary tumors. Journal of Clinical Endocrinology and Metabolism 199071 340-344.

4 Salvatore D, Tu H, Harney JW \& Larsen PR. Type 2 iodothyronine deiodinase is highly expressed in human thyroid. Journal of Clinical Investigation $199698962-968$.

5 Wagner MS, Morimoto R, Dora JM, Benneman A, Pavan R \& Maia AL. Hypothyroidism induces type 2 iodothyronine deiodinase expression in mouse heart and testis. Journal of Molecular Endocrinology 200331 541-550.
6 Canani LH, Capp C, Dora JM, Meyer EL, Wagner MS, Harney JW, Larsen PR, Gross JL, Bianco AC \& Maia AL. The type 2 deiodinase A/G (Thr92Ala) polymorphism is associated with decreased enzyme velocity and increased insulin resistance in patients with type 2 diabetes mellitus. Journal of Clinical Endocrinology and Metabolism 200590 3472-3478.

7 Grozovsky R, Ribich S, Rosene ML, Mulcahey MA, Huang SA, Patti ME, Bianco AC \& Kim BW. Type 2 deiodinase expression is induced by peroxisomal proliferator-activated receptor- $\gamma$ agonists in skeletal myocytes. Endocrinology $2009 \mathbf{1 5 0}$ 1976-1983.

8 Heemstra KA, Soeters MR, Fliers E, Serlie MJ, Burggraaf J, Van Doorn MB, Van Der Klaauw AA, Romijn JA, Smit JW, Corssmit EP \& Visser TJ. Type 2 iodothyronine deiodinase in skeletal muscle: effects of hypothyroidism and fasting. Journal of Clinical Endocrinology and Metabolism 200994 2144-2150.

9 Maia AL, Kim BW, Huang SA, Harney JW \& Larsen PR. Type 2 iodothyronine deiodinase is the major source of plasma $\mathrm{T}_{3}$ in euthyroid humans. Journal of Clinical Investigation 2005115 2524-2533.

10 Coppotelli G, Summers A, Chidakel A, Ross JM \& Celi FS. Functional characterization of the 258 A/G (D2-ORFa-Gly3Asp) human type-2 deiodinase polymorphism: a naturally occurring variant increases the enzymatic activity by removing a putative repressor site in the $5^{\prime}$ UTR of the gene. Thyroid $2006 \mathbf{1 6}$ 625-632.

11 Mentuccia D, Proietti-Pannunzi L, Tanner K, Bacci V, Pollin TI, Poehlman ET, Shuldiner AR \& Celi FS. Association between a novel variant of the human type 2 deiodinase gene Thr92Ala and insulin resistance: evidence of interaction with the Trp64Arg variant of the $\beta$-3-adrenergic receptor. Diabetes $2002 \mathbf{5 1}$ 880-883.

12 Peeters RP, Van Toor H, Klootwijk W, De Rijke YB, Kuiper GG, Uitterlinden AG \& Visser TJ. Polymorphisms in thyroid hormone pathway genes are associated with plasma TSH and iodothyronine levels in healthy subjects. Journal of Clinical Endocrinology and Metabolism 200388 2880-2888.

13 Meulenbelt I, Min JL, Bos S, Riyazi N, Houwing-Duistermaat JJ, Van Der Wijk HJ, Kroon HM, Nakajima M, Ikegawa S, Uitterlinden AG, Van Meurs JB, Van Der Deure WM, Visser TJ, Seymour AB, Lakenberg N, Van Der Breggen R, Kremer D, Van Duijn CM, Kloppenburg M, Loughlin J \& Slagboom PE. Identification of DIO2 as a new susceptibility locus for symptomatic osteoarthritis. Human Molecular Genetics 200817 1867-1875.

14 Gumieniak O, Perlstein TS, Williams JS, Hopkins PN, Brown NJ, Raby BA \& Williams GH. Ala92 type 2 deiodinase allele increases risk for the development of hypertension. Hypertension 200749 461-466.

15 Chistiakov DA, Savost'anov KV \& Turakulov RI. Screening of SNPs at 18 positional candidate genes, located within the GD-1 locus on chromosome 14q23-q32, for susceptibility to Graves' disease: a TDT study. Molecular Genetics and Metabolism 200483 264-270.

16 Guo TW, Zhang FC, Yang MS, Gao XC, Bian L, Duan SW, Zheng ZJ, Gao JJ, Wang H, Li RL, Feng GY, St Clair D \& He L. Positive association of the DIO2 (deiodinase type 2) gene with mental retardation in the iodine-deficient areas of China. Journal of Medical Genetics 200441 585-590.

17 Panicker V, Saravanan P, Vaidya B, Evans J, Hattersley AT, Frayling TM \& Dayan CM. Common variation in the DIO2 gene predicts baseline psychological well-being and response to combination thyroxine plus triiodothyronine therapy in hypothyroid patients. Journal of Clinical Endocrinology and Metabolism 200994 1623-1629.

18 Heemstra KA, Hoftijzer H, Van Der Deure WM, Peeters RP, Hamdy NA, Pereira A, Corssmit EP, Romijn JA, Visser TJ \& Smit JW. The type 2 deiodinase Thr92Ala polymorphism is associated with increased bone turn-over and decreased femoral neck bone mineral density. Journal of Bone and Mineral Research 201025 1385-1391. 
19 Weinstein SP, O'Boyle E \& Haber RS. Thyroid hormone increases basal and insulin-stimulated glucose transport in skeletal muscle. The role of GLUT4 glucose transporter expression. Diabetes 1994 43 1185-1189.

20 Mentuccia D, Thomas MJ, Coppotelli G, Reinhart LJ, Mitchell BD, Shuldiner AR \& Celi FS. The Thr92Ala deiodinase type 2 (DIO2) variant is not associated with type 2 diabetes or indices of insulin resistance in the old order of Amish. Thyroid 200515 1223-1227.

21 Maia AL, Dupuis J, Manning A, Liu C, Meigs JB, Cupples LA, Larsen PR \& Fox CS. The type 2 deiodinase (DIO2) A/G polymorphism is not associated with glycemic traits: the Framingham Heart Study. Thyroid 2007 17 199-202.

22 Grarup N, Andersen MK, Andreasen CH, Albrechtsen A, BorchJohnsen K, Jorgensen T, Auwerx J, Schmitz O, Hansen T \& Pedersen O. Studies of the common DIO2 Thr92Ala polymorphism and metabolic phenotypes in 7342 Danish white subjects. Journal of Clinical Endocrinology and Metabolism 200792 363-366.

23 Stolerman ES \& Florez JC. Genomics of type 2 diabetes mellitus: implications for the clinician. Nature Reviews. Endocrinology 2009 $5429-436$

24 Canani LH, Capp C, Ng DP, Choo SG, Maia AL, Nabinger GB, Santos K, Crispim D, Roisemberg I, Krolewski AS \& Gross JL. The fatty acid-binding protein-2 A54T polymorphism is associated with renal disease in patients with type 2 diabetes. Diabetes 2005 $543326-3330$.

25 American Diabetes Association. Standards of medical care in diabetes - 2010. Diabetes Care 201033 S11-S61.

26 Bonora E, Targher G, Alberiche M, Bonadonna RC, Saggiani F, Zenere MB, Monauni T \& Muggeo M. Homeostasis model assessment closely mirrors the glucose clamp technique in the assessment of insulin sensitivity: studies in subjects with various degrees of glucose tolerance and insulin sensitivity. Diabetes Care 200023 57-63.

27 Zeggini E, Scott LJ, Saxena R, Voight BF, Marchini JL, Hu T, De Bakker PI, Abecasis GR, Almgren P, Andersen G, Ardlie K, Bostrom KB, Bergman RN, Bonnycastle LL, Borch-Johnsen K, Burtt NP, Chen H, Chines PS, Daly MJ, Deodhar P, Ding CJ, Doney AS, Duren WL, Elliott KS, Erdos MR, Frayling TM, Freathy RM, Gianniny L, Grallert H, Grarup N, Groves CJ, Guiducci C, Hansen T, Herder C, Hitman GA, Hughes TE, Isomaa B, Jackson AU, Jorgensen T, Kong A, Kubalanza K, Kuruvilla FG, Kuusisto J, Langenberg C, Lango H, Lauritzen T, Li Y, Lindgren CM, Lyssenko V, Marvelle AF, Meisinger C, Midthjell K, Mohlke KL, Morken MA, Morris AD, Narisu N, Nilsson P, Owen KR, Palmer CN, Payne F, Perry JR, Pettersen E, Platou C, Prokopenko I, Qi L, Qin L, Rayner NW, Rees M, Roix JJ, Sandbaek A, Shields B, Sjogren M, Steinthorsdottir V, Stringham HM, Swift AJ, Thorleifsson G, Thorsteinsdottir U, Timpson NJ, Tuomi T, Tuomilehto J, Walker M, Watanabe RM, Weedon MN, Willer CJ, Illig T, Hveem K, Hu FB, Laakso M, Stefansson K, Pedersen O, Wareham NJ, Barroso I, Hattersley AT, Collins FS, Groop L, Mccarthy MI, Boehnke M \& Altshuler D. Metaanalysis of genome-wide association data and large-scale replication identifies additional susceptibility loci for type 2 diabetes. Nature Genetics $2008 \mathbf{4 0} 638-645$.

28 Review Manager (RevMan) [Computer program]. Version 5.0. Copenhagen: The Nordic Cochrane Centre, The Cochrane Collaboration, 2008.

29 Bax L, Yu LM, Ikeda N, Tsuruta H \& Moons KG. Development and validation of MIX: comprehensive free software for meta-analysis of causal research data. BMC Medical Research Methodology 2006 650.
30 Little J, Higgins JP, Ioannidis JP, Moher D, Gagnon F, Von Elm E, Khoury MJ, Cohen B, Davey-Smith G, Grimshaw J, Scheet P, Gwinn M, Williamson RE, Zou GY, Hutchings K, Johnson CY, Tait V, Wiens M, Golding J, Van Duijn C, Mclaughlin J, Paterson A, Wells G, Fortier I, Freedman M, Zecevic M, King R, InfanteRivard C, Stewart A \& Birkett N. Strengthening the reporting of genetic association studies (STREGA): an extension of the STROBE statement. PLoS Medicine 20096 e22.

31 Moher D, Liberati A, Tetzlaff J \& Altman DG. Preferred reporting items for systematic reviews and meta-analyses: the PRISMA statement. PLoS Medicine 20096 e1000097.

32 Stroup DF, Berlin JA, Morton SC, Olkin I, Williamson GD, Rennie D, Moher D, Becker BJ, Sipe TA \& Thacker SB. Meta-analysis of observational studies in epidemiology: a proposal for reporting. Meta-analysis of Observational Studies in Epidemiology (MOOSE) group. Journal of the American Medical Association 2000283 2008-2012.

33 Scheidegger K, O'Connell M, Robbins DC \& Danforth E Jr. Effects of chronic $\beta$-receptor stimulation on sympathetic nervous system activity, energy expenditure, and thyroid hormones. Journal of Clinical Endocrinology and Metabolism 198458 895-903.

34 Al-Adsani H, Hoffer LJ \& Silva JE. Resting energy expenditure is sensitive to small dose changes in patients on chronic thyroid hormone replacement. Journal of Clinical Endocrinology and Metabolism 199782 1118-1125.

35 Re RN, Kourides IA, Ridgway EC, Weintraub BD \& Maloof F. The effect of glucocorticoid administration on human pituitary secretion of thyrotropin and prolactin. Journal of Clinical Endocrinology and Metabolism 197643 338-346.

36 Bartha T, Kim SW, Salvatore D, Gereben B, Tu HM, Harney JW, Rudas P \& Larsen PR. Characterization of the $5^{\prime}$-flanking and $5^{\prime}$ untranslated regions of the cyclic adenosine $3^{\prime}, 5^{\prime}$-monophosphate-responsive human type 2 iodothyronine deiodinase gene. Endocrinology $2000141229-237$.

37 Celi FS. Brown adipose tissue - when it pays to be inefficient. New England Journal of Medicine 2009360 1553-1556.

38 Manolio TA, Collins FS, Cox NJ, Goldstein DB, Hindorff LA, Hunter DJ, Mccarthy MI, Ramos EM, Cardon LR, Chakravarti A, Cho JH, Guttmacher AE, Kong A, Kruglyak L, Mardis E, Rotimi CN, Slatkin M, Valle D, Whittemore AS, Boehnke M, Clark AG, Eichler EE, Gibson G, Haines JL, Mackay TF, Mccarroll SA \& Visscher PM. Finding the missing heritability of complex diseases. Nature 2009461 747-753.

39 Altshuler D, Hirschhorn JN, Klannemark M, Lindgren CM, Vohl MC, Nemesh J, Lane CR, Schaffner SF, Bolk S, Brewer C, Tuomi T, Gaudet D, Hudson TJ, Daly M, Groop L \& Lander ES. The common PPAR $\gamma$ Pro12Ala polymorphism is associated with decreased risk of type 2 diabetes. Nature Genetics $2000 \mathbf{2 6}$ $76-80$.

40 De Jong FJ, Peeters RP, Den Heijer T, Van Der Deure WM, Hofman A, Uitterlinden AG, Visser TJ \& Breteler MM. The association of polymorphisms in the type 1 and 2 deiodinase genes with circulating thyroid hormone parameters and atrophy of the medial temporal lobe. Journal of Clinical Endocrinology and Metabolism 200792 636-640.

Received 8 June 2010

Accepted 21 June 2010 